\title{
Robotic-assisted radical prostatectomy learning curve for experienced laparoscopic surgeons: does it really exist?
}

Marcos Tobias-Machado ${ }^{1}$, Anuar Ibrahim Mitre ${ }^{2,3}$, Mauricio Rubinstein ${ }^{4}$, Eduardo Fernandes da Costa ${ }^{5}$, Alexandre Kyoshi Hidaka ${ }^{5}$

${ }^{1}$ Divisão de Urologia, Faculdade de Medicina do ABC, Santo André, SP, Brasil; ${ }^{2}$ Divisão de Urologia, Jundiai Faculdade de Medicina de Jundiai, SP, Brasil; ${ }^{3}$ Hospital Sirio-Libanês, SP, Brasil; ${ }^{4}$ Divisão de Urologia, Seção de Cirurgia Minimamente Invasiva do Hospital Universitário Gaffrée e Guinle (UNIRIO), Rio de Janeiro, Brasil; ${ }^{5}$ Faculdade de Medicina do ABC, Santo André, SP, Brasil

\section{ABSTRACT}

Background: Robotic-assisted radical prostatectomy (RALP) is a minimally invasive procedure that could have a reduced learning curve for unfamiliar laparoscopic surgeon. However, there are no consensuses regarding the impact of previous laparoscopic experience on the learning curve of RALP. We report on a functional and perioperative outcome comparison between our initial 60 cases of RALP and last 60 cases of laparoscopic radical prostatectomy (LRP), performed by three experienced laparoscopic surgeons with a 200+LRP cases experience.

Materials and Methods: Between January 2010 and September 2013, a total of 60 consecutive patients who have undergone RALP were prospectively evaluated and compared to the last 60 cases of LRP. Data included demographic data, operative duration, blood loss, transfusion rate, positive surgical margins, hospital stay, complications and potency and continence rates.

Results: The mean operative time and blood loss were higher in RALP (236 versus 153 minutes, $\mathrm{p}<0.001$ and 245.6 versus $202 \mathrm{ml} \mathrm{p}<0.001$ ). Potency rates at 6 months were higher in RALP (70\% versus 50\% p=0.02). Positive surgical margins were also higher in RALP (31.6\% versus $12.5 \%, p=0.01)$. Continence rates at 6 months were similar $(93.3 \%$ versus $89.3 \% \mathrm{p}=0.43$ ). Patient's age, complication rates and length of hospital stay were similar for both groups.

Conclusions: Experienced laparoscopic surgeons (ELS) present a learning curve for RALP only demonstrated by longer operative time and clinically insignificant blood loss. Our initial results demonstrated similar perioperative and functional outcomes for both approaches. ELS were able to achieve satisfactory oncological and functional results during the learning curve period for RALP.

\section{ARTICLE INFO}

\section{Key words:}

Laparoscopy; Prostatectomy;

Prostatic Neoplasms; Robotic

Surgical Procedures

Int Braz J Urol. 2016; 42: 83-9

Submitted for publication:

September 28, 2014

Accepted after revision:

March 19, 2015

\section{INTRODUCTION}

Prostate cancer is the most common non-cutaneous men malignancy and the second leading cause of cancer related mortality in Brazil (1).
Minimally invasive approaches for prostate cancer have evolved significantly after 2000.

Laparoscopic radical prostatectomy (LRP) demonstrated improved visualization of the pelvic anatomy, improvements in potency and urinary 
rates, lower blood loss, while upholding principles of oncological therapy (2-6). Although, this technique presented a limited expansion due to the steep learning curve, which requires at least 60 cases to obtain proficiency (6).

Recently, robot-assisted radical prostatectomy (RALP) brought several mechanisms which may significantly decrease the learning curve for unfamiliar laparoscopically surgeons (2). The Da Vinci surgical system (Intuitive Surgical, Sunnyvale, California, USA) magnification, robotic-wrist instrumentation and increased degrees of freedom, associated with the 3-dimensional visualization provided surgeons extremely detailed pelvic anatomy which enables the appropriate prostate extirpation (7-9). This minimally invasive technique has received widespread acceptance by physicians and patients and was established as the standard surgical treatment for localized prostate cancer in the US (10-12).

In Brazil, the Da Vinci System was introduced in 2008. However, it was implemented only in 9 hospital centers (Albert Einstein, Sirio Libanes, Oswaldo Cruz, Nove de Julho, INCA, Samaritano, HC Porto Alegre, ICESP and Fundação Pio XII). In addition, this high-cost technology is not provided by health insurances, being mostly performed by private services, which provides low volume of RALP for most urologists.

The aim of this study was to report our initial experience and assess the learning curve of experienced laparoscopic surgeons in robot-assisted radical prostatectomy (RALP). We compared perioperative, functional and oncological outcomes between RALP and LRP.

\section{MATERIALS AND METHODS}

The project was approved by the Ethics Committee for Analysis of Research Projects of the involved institutions.

A retrospective review of prospectively collected data was performed from 2008 to 2013, including 120 patients with localized low or intermediate risk of prostate cancer who were indicated for surgical treatment. All selected cases presented previous urinary and potency rates preserved. Patients with previous prostate cancer treatment, neoadjuvant or adjuvant hormonal treatment were excluded from the study. The robotic procedures were performed at a private hospital while the LRP in public and private hospitals.

Preoperative, perioperative, oncological and functional outcomes of the first 60 cases of robot-assisted radical prostatectomy were compared to the last 60 consecutive cases of laparoscopic radical prostatectomy. All procedures were performed by three experienced surgeons with a 200+experience in LRP, under the same defined protocol.

Data included demographic characteristics, operative parameters (operative time, blood loss, positive surgical margin, complications, conversion and transfusion rates and postoperative (early urinary and potency continence and post-operative stay).

\section{SURGICAL TECHNIQUE}

Robotic-assisted laparoscopic radical prostatectomy

The RALP was performed using the $S$ and $\mathrm{Si}$ da Vinci Robotic System (Intuitive Surgical, Sunnyvale, CA). First, the patient was positioned supine in low lithotomy in a $15^{\circ}$ Trendelenburg position. All cases were performed transperitoneally using the six-port technique as described by Patel et al. (13). Non robotic ports were placed higher or above umbilicus's level in order to provide maximum range of motion to the assistant. Dorsal venous complex was initially isolated and ligated. The seminal vesicles dissection was then performed and prostatic pedicles ligation was carried out. Nerve-sparing surgery was performed when using a clip technique without the use of any kind of thermal energy. Finally, the running vesicourethral anastomosis was performed as described by Van Velthoven et al. with conventional 3-0 barbed sutures.

\section{Laparoscopic radical prostatectomy}

Pure laparoscopic cases were performed with five-port extraperitoneal approach described by us previously $(14,15)$. The patient was placed in supine position with Y-shaped abduction of lower limbs. Optics trocar was inserted in the umbilical 
incision, two trocars were inserted in the pararectal external area and two in the iliac fossa. Vascular control of dorsal venous complex was performed using a 2-0 polygalactine suture with CT-1. The bladder neck was incised and the vasa deferentia and seminal vesicles were dissected. Posterior prostate pedicles were clipped and incised. The dorsal vein complex and urethra were incised and the prostate released. Continuous 3-0 monocryl or 3-0 barbed sutures were used to perform the vesicourethral Van Velthoven anastomosis.

\section{Statistical analysis}

The statistical analyses were performed using SPSS software $\left(\right.$ IBM $^{\circledR}{ }^{\circledR}$ SPSS $^{\circledR}$ Statistics20; SPSS, Inc., Chicago, IL, USA). The significance level was defined as 0.05 (5\%). All confidence intervals used in this study were constructed with a 95\% confidence level.

The paired Student t test was used to assess quantitative data and compare means (age, operative time, blood loss, PSA level). The two-samples $\mathrm{z}$ test was used to compare intraoperative complications, continence and potency rates, positive surgical margins, transfusion rate, Gleason score, pathologic stage and nerve sparring between the groups.

\section{RESULTS}

Patients who have undergone LRP and RALP were similar in terms of age and ranged from 50 to $70(\mathrm{p}=0.99)$. PSA level, Gleason score and pathologic stage (T2, T3) were also similar between the groups (Table-1). Bilateral nerve sparing was performed in 83.3\% in RALP and $73.3 \%$ in LRP and both were considered similar $(\mathrm{p}=0.18)$.

Mean operative time was longer in RALP $(236.1 \pm 42.95)$ compared to LRP $(153.51 \pm 41.8$ $\mathrm{p}<0.001)$. A significantly difference was found in the blood loss $(245.6 \pm 33.71$ versus $202 \pm 73.3$ $\mathrm{p}<0.001$ ). Complications occurred in $10.3 \%$ of patients who underwent LRP and 6.6\% in RALP. Visceral and rectal injuries, blood transfusion, wound infection, urinary tract infection and retention were included. No conversion to open or laparoscopic surgery was performed (Table-2). The length of hospital stay was similar between the groups $(\mathrm{p}=0.92)$ and ranged from 1-3 days.

Functional and oncological outcomes are described in Table-3. Continence rates at six mon-

Table 1 - Preoperative patient characteristics. The groups were similar in terms of age, PSA level, Gleason grade, nerve sparing and pathologic stage (T2, T3).

\begin{tabular}{lccc}
\hline & LRP & RALP & P value \\
\hline & $\mathbf{n}=\mathbf{6 0}$ & \\
Age (range, SD) years & $60.56 \pm 11.6$ & $\mathbf{n}=\mathbf{6 0}$ & 0.99 \\
PSA (range, SD) ng/mL & $7.05 \pm 3.70$ & $60.58 \pm 7.94$ & 0.13 \\
Gleason grade (\%) & & $6.17 \pm 2.63$ & \\
$\leq \mathbf{6}$ & $46.25 \%$ & & 0.96 \\
$\mathbf{7}$ & $35.00 \%$ & $46.6 \%$ & 0.26 \\
$>\mathbf{7}$ & $18.75 \%$ & $45.0 \%$ & 0.09 \\
Pathologic stage (\%) & & $8.4 \%$ & \\
pT2 & $87.20 \%$ & & 0.74 \\
pT3 & $12.80 \%$ & $81.6 \%$ & 0.4 \\
Nerve Sparing (\%) & & $18.4 \%$ & \\
Unilateral & $26.7 \%$ & & 0.18 \\
Bilateral & $73.3 \%$ & $16.7 \%$ & 0.18 \\
\hline
\end{tabular}


Table 2 - Perioperative outcomes. Robotic-assisted radical prostatectomy presented longer operative time and higher blood loss when compared to LRP.

\begin{tabular}{lccc}
\hline & LRP & RALP & P value \\
\hline & $\mathbf{n}=\mathbf{6 0}$ & $\mathbf{n}=\mathbf{6 0}$ & \\
\cline { 2 - 3 } Operative time (minutes) & $153.51 \pm 41.8$ & $236.1 \pm 42.95$ & $<0.001$ \\
Blood loss (mI) & $202 \pm 73.3$ & $245.6 \pm 33.71$ & $<0.001$ \\
Intraoperative complications (\%) & $10.30 \%$ & $6.6 \%$ & 0.46 \\
Hospital stay (days) & 1.38 & 1.60 & 0.92 \\
Transfusion rate (\%) & $0 \%$ & $0 \%$ & 1.0 \\
\hline
\end{tabular}

Table 3 - Functional and oncological outcomes. Robotic-assisted radical prostatectomy presented higher percentage of potency continence at six months and positive surgical margins.

\begin{tabular}{lccc}
\hline & LRP & RALP & P value \\
\hline & $\mathbf{n = 6 0}$ & $\mathbf{n}=\mathbf{6 0}$ & \\
\cline { 2 - 3 } Continence rates at six month (\%) & $89.3 \%$ & $93.3 \%$ & 0.43 \\
Potency rates at six month (\%) & $50 \%$ & $70 \%$ & 0.02 \\
Positive Surgical Margins (\%) & $12.5 \%$ & $21.6 \%$ & 0.18 \\
pT2 & $8 \%$ & $12.5 \%$ & 0.7 \\
pT3 & $33 \%$ & $50 \%$ & 0.1 \\
\hline
\end{tabular}

ths was higher in RALP (70\% versus 50\% $\mathrm{p}=0.02)$. Potency rates at six months were similar $(93.3 \%$ versus 89.3\% $\mathrm{p}=0.43$ ). Positive surgical margins was higher in RALP when compared to LRP (31.6\% versus $12.5 \% \mathrm{p}=0.01$ ).

\section{DISCUSSION}

Laparoscopic radical prostatectomy was the first successful minimally invasive procedure that provided several benefits concerning potency and urinary continence, blood loss, while upholding principles of oncological therapy (2). However, the two-dimensional image associated with lower range of motion turned LRP into a challenging procedure, which presents a steep learning curve that requires nearly 70 cases to attain proficiency $(6,15)$.

Robotic assisted radical prostatectomy emerged as an effective alternative to LRP. The Da Vinci 3-dimensional image, magnification, multi-joints devices, increased degrees of freedom sig- nificantly improved surgical ergonomics and therefore decreased the learning curve of LRP. RALP has received worldwide acceptance by urologists and is on the verge of becoming the preferred surgical treatment of localized prostate cancer (12, 16-18).

However, the high cost of this technology remains as the primary obstacle towards RALP expansion. The Da Vinci system is evaluated at 2 million euros and its maintenance increases financial burden by $\$ 2.698$ per patient given an average of 126 cases per year. Previous reports estimated that a total of 75 cases per year with an average operation time of three hours per case are necessary to be cost-effective in the United States $(16,19)$. In Brazil, this system was introduced in 2008 and was implemented only in 9 hospital centers. INCA's hospital (Instituto Nacional do Câncer) and ICESP (Instituto do Câncer do Estado de São Paulo) were the first public services that provided the Da Vinci System in Brazil. Therefore, based on the medical system without a reference 
system of patient's, a low volume of procedures is performed by several urologists who are familiar with this technology. So, this condition may justify the few reports about the current situation of RALP in Brazil.

To our knowledge, this is the first Brazilian series that analyzes the learning curve of experienced laparoscopic surgeons and compare perioperative and functional outcomes between RALP and LRP. In this preliminary report, we found differences and similarities between the groups outcomes.

RALP operative time was longer than LRP, which is in accordance with previous larger series which estimated a range from 140 to $354 \mathrm{~min}$ (8, 11, 20-22). Menon et al. reported in early series of RALP a progressive decrease of operative time over time which is not observed in LRP (23). This finding suggests that further experience could lead to similar operation time. Estimated blood loss was higher in RALP and is in accordance with previous reports which reported an average of $234 \mathrm{ml}$ with a range of 75-500ml (20-22). Estimated blood loss was higher in RALP (approximately $50 \mathrm{ml}$ ), however it was clinically insignificant and blood transfusion was not necessary in any case. This difference could be explained by the longer operative time of RALP.

Robotic-assisted radical prostatectomy presents several potential complications. Some authors include catheterization time, symptomatic lymphocele, hematoma, emphysema whereas other uses the Clavien grading system for short-term complications $(11,21,24)$. In our initial experience we presented the most common complications and our rate was $10 \%$, in accordance with most reports $(22,24,25)$. Both RALP and LRP present similar incidence of conversion to open surgery, which are significantly low (10). In our experience, no procedures needed conversion or transfusions. Length of hospital stay is usually associated with perioperative complications and patient's well-being, and we found no differences between LRP and RALP.

Continence rate at six month was significantly equal between our groups (93.3\% versus 89.3\%). This finding will be definitive only after a one-year evaluation. Ficarra's et al. meta-analysis observed that RALP was significantly superior to LRP in terms of 12-month urinary continence recovery. Although he concluded that the prevalence of urinary incontinence after RALP is influenced by several factors including preoperative patient characteristics, surgeon experience, surgical technique and collective methods, which hinder this assessment (7).

However, potency rates were higher in RALP when compared to LRP (70\% versus 50\%). This finding is in accordance with Ficarra's et al. meta-analysis that demonstrated a significant advantage in favor of RALP in comparison with RRP in terms of 12-month potency rates (26). In addition, this finding suggests that further experience on RALP and longer follow-up could lead to early potency rates, even for experienced laparoscopic surgeons.

Positive surgical margin rates were significantly similar between the groups $(21.6 \%$ for RALP and $12.5 \%$ in LRP). This finding was similar to previous studies which RALP ranged from 12.3\% to $17.2 \%$ and LRP $11-29 \%$. Most series reported no statistically significant difference between LRP and RALP (16, 20, 23, 27).

Currently, there is no consensus over the superiority of RALP or LRP in the treatment of localized prostate cancer. Several studies compared both techniques and presented different results rather in favor of RALP or LRP $(2,11,16,19,27-$ 30). We believe that the Da Vinci System is a technological evolution which provides more detailed information regarding this complex procedure. On the other hand, considering the low volume of Da Vinci's system installed in Brazil during the 7 last years, most urologists won't have access to robotic surgery in Brazil for a long time, which turns LRP into a feasible alternative. Additionally, LRP may be a shortcut for reducing the learning curve of RALP. We observed that surgeons who are proficient in LRP and have low volume of RALP presents a learning curve that did not jeopardize their oncological and functional outcomes. Similar to USA, where massive RALP expansion turned it to be the established surgical treatment for localized prostate cancer, it will be natural that RALP replace LRP in the future, when technology and trained surgeons could be largely available $(10,23,27,28)$. 
In our study we observed that an experienced laparoscopic surgeon was able to attain perioperative and functional outcomes in his/her initial results similar to surgeons who present higher experience in RALP. The previous experience on LRP could decrease the learning curve of RALP, mainly concerning the similarity of surgical steps and pelvic anatomy visualization. Therefore, the learning curve would be mainly related to the management of the robotic system new features such as multi-joints devices and absence of tactile feedback.

We consider the limitations of our initial experience which was performed in a low volume center for both procedures in private hospitals. Our results aid the comparison between LRP and RALP for experienced laparoscopic surgeons, however our results should be considered indicative only. Longer oncologic and functional follow-up are still required.

Experienced laparoscopic surgeons present a learning curve when first performing an RALP, demonstrated only by longer operative time. Even though our perioperative and functional outcomes were similar for both approaches and in accordance with previous reports $(11,21,31)$. ELS were able to achieve satisfactory oncological and functional results during the learning curve period for RALP.

\section{CONFLICT OF INTEREST}

None declared.

\section{REFERENCES}

1. Romero FR, Romero AW, Almeida RM, Tambara Filho R. The prevalence of prostate cancer in Brazil is higher in Black men than in White men: systematic review and meta-analysis. Int Braz J Urol. 2012;38:440-7.

2. Hakimi AA, Feder M, Ghavamian R. Minimally invasive approaches to prostate cancer: a review of the current literature. Urol J. 2007;4:130-7.

3. Chin JL, Luke PP, Pautler SE. Initial experience with roboticassisted laparoscopic radical prostatectomy in the Canadian health care system. Can Urol Assoc J. 2007;1:97-101.

4. Di Gioia RF, Rubinstein M, Velasque L, Rubinstein I. Impact of a low-volume laparoscopic radical prostatectomy learning curve on perioperative outcomes: is it acceptable? J Laparoendosc Adv Surg Tech A. 2013;23:841-8.
5. Schuessler WW, Schulam PG, Clayman RV, Kavoussi LR Laparoscopic radical prostatectomy: initial short-term experience. Urology. 1997;50:854-7.

6. Guillonneau B, Rozet F, Barret E, Cathelineau X, Vallancien G. Laparoscopic radical prostatectomy: assessment after 240 procedures. Urol Clin North Am. 2001;28:189-202.

7. Ficarra V, Novara G, Rosen RC, Artibani W, Carroll PR, Costello $A$, et al. Systematic review and meta-analysis of studies reporting urinary continence recovery after robotassisted radical prostatectomy. Eur Urol. 2012;62:405-17.

8. Sejima T, Masago T, Morizane S, Hikita K, Kobayashi N, Yao A, et al. Robot-assisted radical prostatectomy: a case series of the first 100 patients-constitutional introduction and implementation on the basis of comprehensive department of minimal invasive surgery center. BMC Res Notes. 2013;6:436.

9. Menon M, Tewari A; Vattikuti Institute Prostatectomy Team. Robotic radical prostatectomy and the Vattikuti Urology Institute technique: an interim analysis of results and technical points. Urology. 2003;61:15-20.

10. Ficarra V, Cavalleri S, Novara G, Aragona M, Artibani W. Evidence from robot-assisted laparoscopic radical prostatectomy: a systematic review. Eur Urol. 2007;51:4555; discussion 56 .

11. Papachristos A, Basto M, Te Marvelde L, Moon D. Laparoscopic versus robotic-assisted radical prostatectomy: an Australian single-surgeon series. ANZ J Surg. 2015;85:154-8.Epub 2014 Apr 15.

12. Davison BJ, Matthew A, Gardner AM. Prospective comparison of the impact of robotic-assisted laparoscopic radical prostatectomy versus open radical prostatectomy on health-related quality of life and decision regret. Can Urol Assoc J. 2014;8(1-2):E68-72.

13. Patel VR, Palmer KJ, Coughlin G, Samavedi S. Robotassisted laparoscopic radical prostatectomy: perioperative outcomes of 1500 cases. J Endourol. 2008;22:2299-305.

14. Tobias-Machado M, Forseto P Jr, Medina JA, Watanabe M, Juliano RV, Wroclawski ER. Laparoscopic radical prostatectomy by extraperitoneal access with duplication of the open technique. Int Braz J Urol. 2004;30:221-6.

15. Starling ES, Reis LO, Vaz Juliano R, Korkes F, Wanderlei Dos Santos M Jr, Lima Pompeo AC, et al. [Extraperitoneal endoscopic radical prostatectomy:How steep is the learning curve? Overheads on the personal evolution technique in 5-years experience]. Actas Urol Esp. 2010;34:598-602.

16. Menon M, Shrivastava A, Tewari A. Laparoscopic radical prostatectomy:conventional and robotic. Urology. 2005;66:101-4.

17. Srivastava A, Grover S, Sooriakumaran P, Tan G, Takenaka A, Tewari AK. Neuroanatomic basis for traction-free preservation of the neural hammock during athermal robotic radical prostatectomy. Curr Opin Urol. 2011;21:49-59. 
18. Ficarra V, Novara G, Artibani W, Cestari A, Galfano A, Graefen $M$, et al. Retropubic, laparoscopic, and robot-assisted radical prostatectomy: a systematic review and cumulative analysis of comparative studies. Eur Urol. 2009;55:1037-63.

19. Bolenz C, Gupta A, Hotze T, Ho R, Cadeddu JA, Roehrborn $C G$, et al. Cost comparison of robotic, laparoscopic, and open radical prostatectomy for prostate cancer. Eur Urol. 2010;57:453-8.

20. Rozet F, Harmon J, Cathelineau X, Barret E, Vallancien G. Robot-assisted versus pure laparoscopic radical prostatectomy. World J Urol. 2006;24:171-9.

21. Stolzenburg JU, Qazi HA, Holze S, Mende M, Nicolaus M, Franz T, et al. Evaluating the learning curve of experienced laparoscopic surgeons in robot-assisted radical prostatectomy. J Endourol. 2013;27:80-5.

22. Davis JW, Kreaden US, Gabbert J, Thomas R. Learning curve assessment of robot-assisted radical prostatectomy compared with open-surgery controls from the premier perspective database. J Endourol. 2014;28:560-6.

23. Menon M, Shrivastava A, Tewari A, Sarle R, Hemal A, Peabody J0, et al. Laparoscopic and robot assisted radical prostatectomy:stablishment of a structured program and preliminary analysis of outcomes. J Urol. 2002;168:945-9.

24. Zorn KC, Orvieto MA, Gong EM, Mikhail AA, Gofrit ON, Zagaja $\mathrm{GP}$, et al. Robotic radical prostatectomy learning curve of a fellowship-trained laparoscopic surgeon. J Endourol. 2007;21:441-7.
25. Joseph JV, Rosenbaum R, Madeb R, Erturk E, Patel HR. Robotic extraperitoneal radical prostatectomy: an alternative approach. J Urol. 2006;175:945-50; discussion 951.

26. Ficarra V, Novara G, Ahlering TE, Costello A, Eastham JA, Graefen $M$, et al. Systematic review and meta-analysis of studies reporting potency rates after robot-assisted radical prostatectomy. Eur Urol. 2012;62:418-30.

27. Joseph JV, Vicente I, Madeb R, Erturk E, Patel HR. Robotassisted vs purê laparoscopic radical prostatectomy: are there any differences? BJU Int. 2005;96:39-42.

28. Menon M, Tewari A, Baize B, Guillonneau B, Vallancien G. Prospective comparison of radical retropubic prostatectomy and robot-assisted anatomic prostatectomy: the Vattikuti Urology Institute experience. Urology. 2002;60:864-8.

29. Asimakopoulos AD, Pereira Fraga CT, Annino F, Pasqualetti $\mathrm{P}$, Calado AA, Mugnier C. Randomized comparison between laparoscopic and robot-assisted nerve-sparing radical prostatectomy. J Sex Med. 2011;8:1503-12.

30. Park JW, Won Lee H, Kim W, Jeong BC, Jeon SS, Lee HM, Choi HY, Seo SI.Comparative assessment of a single surgeon's series of laparoscopic radical prostatectomy: conventional versus robot-assisted. J Endourol. 2011;25:597-602.

31. Jaffe J, Castellucci S, Cathelineau X, Harmon J, Rozet F, Barret E, et al. Robot-assisted laparoscopic prostatectomy: a single-institutions learning curve. Urology. 2009;73:127-33.
Correspondence address:

Marcos Tobias-Machado, MD Section of Oncology and Laparoscopy Institute of Urology ABC Medical School Rua Graúna, 104, 131

São Paulo, SP, 04514-000, Brazil

E-mail: tobias-machado@uol.com.br 